\title{
A COOPTAÇÃO NEOCOLONIAL DA AGÊNCIA POR MEIO DA PATOLOGIZAÇÃO DA POBREZA, DA DIVERSIDADE E DA DESIGUALDADE NOS EUA E COMO ENFRENTÁ-LA COM UMA EDUCAÇÃO ATIVISTA TRANSFORMADORA
}

\section{THE NEOCOLONIAL COOPTION OF AGENCY THROUGH THE PATHOLOGIZATION OF POVERTY, DIVERSITY AND INEQUALITY IN THE UNITED STATES AND HOW TO FACE IT WITH A TRANSFORMATIVE, ACTIVIST EDUCATION}

\author{
Soraya Franzoni Conde* \\ Eduardo Vianna* \\ Araminta Pole ${ }^{* \star *}$
}

\begin{abstract}
RESUMO: Este trabalho aborda a relação entre a patologização dos(as) estudantes oriundos(as) da classe trabalhadora, de imigrantes e de minorias étnico-raciais nos Estados Unidos e a cooptação da agência dessa população historicamente explorada e submetida a opressões sociais e educacionais. Para isso, utilizamos a concepção de agência desde o Posicionamento Ativista Transformador (Transformative Activist Stance - TAS), desenvolvido por Stetsenko (2017), a filosofia da práxis em Marx (1989), a teoria histórico-cultural de Vygotsky (2002) e a perspectiva anticolonialista de Freire (2019) e Quijano (2019). Primeiramente, apresentamos as condições de vida e de trabalho de estudantes vulneráveis e latinos(as) em Nova York e nos Estados Unidos, depois tratamos um conjunto de discussões teóricas oriundas de pesquisas sobre o contexto da patologização da pobreza, do déficit, da diferença e da desigualdade social. Em seguida, apresentamos as histórias de vida e de escolarização de estudantes do Community College da City University of New York (CUNY) diagnosticados(as) como deficientes de aprendizagem e a sua luta dentro do sistema educacional americano. O processo de patologização daqueles(as) que não se enquadram no padrão branco e supremacista norte-americano culmina numa nova
\end{abstract}

* Realizou pós-doutorado em Psicologia e Educação Urbana pela City University of New York (EUA). Professora da Universidade Federal de Santa Catarina (UFSC). Contato: sorayafconde@gmail.com. A coleta dos dados foi feita durante o estágio da primeira autora deste artigo como professora visitante na City University of New York, com bolsa e financiamento Capes/PRINT/UFSC. O projeto individual da autora também recebe apoio financeiro da Fundação de Amparo à Pesquisa e Inovação do Estado de Santa Catarina (Fapesc), edital 06/2016.

** Doutorado em Psicologia do Desevolvimento pela City University of New York (EUA). Professor de Psicologia e Educação Urbana do Graduate Center da City University of New York e professor de Psicologia no LaGuardia Community College da City University of New York. Contato: evianna@lagcc.cuny.edu

*** Estudante de Psicologia no LaGuardia College da City University of New York (EUA). Contato: araminta.poole@gmail.com 
forma de colonialismo (o Sul dentro do Norte Global), resultante na cooptação da agência crítica e transformadora daqueles(as) que, a priori, poderiam ser o motor da transformação do sistema escolar que os(as) oprime.

Palavras-chave: Neocolonialismo. Deficiência. Agência. Educação.

ABSTRACT: This work addresses the relationship between the pathologization of students from the working class, immigrants and ethnic-racial minorities in the United States and the co-optation of the agency of this historically exploited population and subjected to social and educational oppression. For this, we used the concept of agency from the Transformative Activist Stance (TAS), developed by Stetsenko (2017), the philosophy of praxis in Marx (1989), the historical-cultural theory of Vygotsky (2002) and the anti-colonialist perspective of Freire (2019) and Quijano (2019). First, we present the living and working conditions of vulnerable students, especially Latinos, in New York and the United States, then we discuss a set of theoretical issues arising from research on the context of the pathologization of poverty, deficit, difference and social inequality. Next, we present the life and schooling histories 2 ? of students from a Community College at City University of New York (CUNY) diagnosed as learning disabled and their struggle within the American educational system. Our aim is to reveal how how the pathologization process produces students who come to "not fit in" the North American White supremacist sociocultural standard, which amounts to a new form of colonialism (the South within the Global North), resulting in the co-optation of the critical and transformative agency of precisely of the marginalized who, potentially, are uniquely positioned to be the engine of the transformation of the school system that oppresses them.

Keywords: Neocolonialism. Deficiency. Agency. Education.

\section{APRESENTAÇÃO}

O objetivo deste texto é refletir sobre a relação entre a patologização de estudantes oriundos(as) da classe trabalhadora, de imigrantes e de minorias étnico-raciais nos Estados Unidos e a cooptação da agência dessa população historicamente explorada e submetida a opressões sociais e educacionais. Para isso, utilizamos a concepção de agência desde o Posicionamento Ativista Transformador (Transformative Activist Stance - TAS), desenvolvido por Stetsenko (2017), a filosofia da práxis em Marx (1989), a teoria históricocultural de Vygotsky (2002) e a perspectiva anticolonialista de Freire (2019) e Quijano (2019).

Recorrendo aos dados sobre a situação de vida de alunos(as) sócio e economicamente vulneráveis, oriundos(as) da classe trabalhadora americana, de imigrantes e de minorias étnico-raciais - a população típica dos Community 
Colleges -, bem como aos relatos de estudantes imigrantes do Community College La Guardia, de Nova York, coletados durante 2020, ao longo dos nossos estágios como professores visitantes, no Brasil e nos Estados Unidos, percebemos como dificuldades de sobrevivência e diversidades de aprendizagem são tratadas como patologias individuais a serem combatidas, adaptadas e medicalizadas. Assim, a agência estudantil crítica, ativista e transformadora é cooptada e tratada como desvio a ser combatido, a fim de fazer com que tais estudantes possam se adaptar às práticas institucionais vigentes, em nome de uma escola e de uma sociedade 'harmônicas'. Essa abordagem posiciona cada estudante como o foco individual do problema a ser remediado, reduzindo-o a uma patologia (de cunho psicobiológico) e evitando abordar dificuldades de aprendizagem de forma mais ampla, relacional e situada em práticas de ensino-aprendizagem e institucionais. Em tal recorte, o(a) estudante é entendido(a) fora do contexto social de sua existência e, como condição de sobrevivência, incorpora valores e discursos favoráveis à própria opressão. Conforme estudado previamente pelo segundo autor e seu grupo de pesquisa, ao receberem diagnósticos de desordens psíquicas ou deficiências (p. ex., deficiência de aprendizagem) e ao serem encaminhados(as) a serviços especiais ou de saúde mental, tais estudantes passam a se ver e se posicionar como inferiores aos(às) alunos(as) supostamente normais, julgando seu potencial como intrinsicamente limitado por suas patologias ou deficiências. Esse tipo de prática, amplamente difundida nas instituições de ensino dos EUA, encontra-se ancorada em abordagens teóricas psicológicas tradicionais, que idealizam o indivíduo como sujeito dotado de processos cognitivos inerentes à sua mente, cujo funcionamento é independente de relações e contextos, e reduzida a processos biológicos como o processamento neuronal. Ou seja, esse arcabouço conceitual, proveniente de teorias psicológicas de origem europeia e sustentado por noções de funcionamento psíquico universal e de superioridade eurocêntrica, leva ao estabelecimento de relações assimétricas de poder e a construção de hierarquias, que levam à desigualdades e à subalternidades de povos e ideias típicas de processos coloniais.

Como descreve Quijano (2019, p. 151): 
La colonialidad es uno de los elementos constituivos y específicos del padrón mundial de poder capitalista. Se funda en la imposición de una clasificación racial/étnica de la población del mundo como piedra angular de dicho patrón de poder, y opera en cada uno de los planos, ámbitos y dimensiones, materiales y subjetivas, de la existencia cotidiana y a escala social.

A discussão que Boaventura de Sousa Santos (2019) faz sobre a socialidade metropolitana e a colonial, oferece uma boa lente para entendermos a complexa e contraditória dinâmica de identificação (ou apropriação/internalização) e resistência da patologização de alunos(as) que enfrentam desafios em sua educação. Seguindo essa discussão, podemos ver com a marginalização dos(as) alunos(as) de Community Colleges diagnosticados(as) com distúrbios psicológicos ou deficiência estira o limite entre exclusão abissal e não abissal, pois ameaça cruzar a zona de não ser à que se refere Fanon (1968). De um lado, pode-se argumentar que alunos(as) de uma faculdade comunitária, em uma metrópole global como Nova York, ocupam uma sociabilidade metropolitana inerente à sua posição de classe enquanto estudantes que chegaram a ter acesso à educação pós-secundária, participam de uma comunidade estudantil e, em princípio, têm acesso a recursos e mecanismos para lutar contra a exclusão.

No sentido oposto à opressão colonialista, abissal e individualista citada por Quijano (2019) e Boaventura (2019), encontra-se a abordagem de agência humana desde o TAS, de Stetsenko (2017). Nessa perspectiva, teoria e prática, natureza e cultura, ação e pensamento, indivíduo e coletivo constituem um todo estruturado, pelo qual o mundo vem sendo constantemente criado e transformado:

[...] the world constantly created and recreated, invented and reinvented, changed and transformed and, thus - realized by and through human agency which is a this worldly process of contributing to social changes that bring forth world [...] the stream of social collaborative practices through agentive contribution does not imply that individuals find this practices as a preformed and static realm "out there [...]. (STETSENKO, 2017, p. 206). 
Conforme Stetsenko (2017), o ser humano age, cria e transforma constantemente o mundo, ao mesmo tempo em que é constituído por práticas sociais compartilhadas na vida cotidiana, em meio à qual ocorrem relações, trocas, interações, lutas e buscas individuais-coletivas. Em nosso entendimento, essas práticas não são fixas ou inertes, nem dadas a priori pela biologia ou pela iluminação humana, mas estão em constante movimento, de acordo com os engajamentos práticos e buscas diárias de cada um(a).

Stetsenko (2017) recorda que a ideia passiva de ser humano adaptado e hierarquizado é incorporada por meio de afirmações corriqueiras como, por exemplo, "eu estou no trânsito". Tal sentença, presente em nossas práticas cotidianas, expressa uma compreensão fragmentada e determinada da natureza humana e fundamenta o pensamento educacional conservador e colonialista, interessado em diminuir nosso potencial ativo e transformador. Nesse sentido, "eu estou no trânsito" necessita ser trocado por "eu sou o trânsito" e, assim, reposicionar o ativismo humano nos contextos sociais (STETSENKO, 2017, grifos nossos).

Ao recuperar a compreensão do trabalho para fundamentar sua explicação de agência e o posicionamento ativista transformador, a autora destaca que, ao mudarmos as circunstâncias, modificamos nossa própria natureza, num movimento incessante, dialético e contínuo. Assim, cada pessoa modifica simultaneamente a sí mesma e ao mundo num processo único, indissociável e inigualável. Os seres humanos não estão no mundo, mas são o próprio mundo, modificado segundo suas próprias ações e intenções: "Agency is about changing how the world is changing us" (STETSENKO, 2017, p. 225).

Este texto é produto de pesquisas, estudos e intercâmbios desenvolvidos no âmbito do projeto CAPES-PRINT - UFSC 'Repositórios de Práticas interculturais: proposições para pedagogia decolonial', durante o ano de 2020, quando os(as) autores(as) atuaram como visitantes do exterior na Universidade Federal de Santa Catarina e na City University of New York (CUNY). Ele está estruturado da seguinte forma: na primeira parte, apresentamos as condições de vida e de trabalho dos(as) estudantes vulneráveis e latinos(as) em Nova York e nos Estados Unidos, dados estes que 
foram coletados durante a Pandemia de Covid-19, que afetou duramente esse grupo social, em razão das suas condições de vida e da exploração no trabalho à que estão cotidianamente submetidos(as). Na segunda parte, tratamos de um conjunto de discussões teóricas, oriundas de pesquisas sobre o contexto da patologização da pobreza, do déficit, da diferença e da desigualdade social. Em seguida, apresentamos as histórias de vida e de escolarização de estudantes do Community College da CUNY diagnosticados(as) como deficientes de aprendizagem e a sua luta dentro do sistema educacional americano. Nesse sentido, refletimos sobre como o processo de patologização daqueles que não se enquadram no padrão branco e supremacista norte-americano culmina numa nova forma de colonialismo (o Sul dentro do Norte Global), resultando na cooptação da agência crítica e transformadora daqueles(as) que, a priori, poderiam ser o motor da transformação do sistema escolar que os(as) oprime. Por último, evidenciamos o encontro dos(as) estudantes com a Peer Activist Learning Community (PALC), na qual, a partir do suporte coletivo e do espírito de solidariedade e camaradagem, os(as) estudantes participam de um processo de aprendizagem compartilhada em que a opressão historicamente vivida é gradativamente inserida dentro do contexto de lutas históricas.

À medida que os(as) alunos vão tendo acesso a conceitos críticoteóricos enquanto ferramentas culturais, por meio de discussões e da construção colaborativa de currículo, sua resistência a práticas institucionais coalesce no nexo da agência collectividual (STETSENKO, 2013) e deixa de ser cooptada pela patologização e medicalização, transformando-se numa crítica ativista contra o sistema e voltada a um projeto de futuro sem os sistemas de opressão de classe, etnia, raça, sexo, gênero, sexualidade e deficiência.

\section{O SUL NO NORTE GLOBAL E A SITUAÇÃO DO COMMUNITY COLLEGE DA CUNY}

Os Estados Unidos da América são considerados o país mais rico do mundo, sendo responsável por $25 \%$ da riqueza produzida no globo terrestre e por grandes investimentos nas áreas da ciência e da tecnologia, que resultam numa potente e aterrorizante indústria bélica e em arrojadas pesquisas 
espaciais. Não obstante, o país também ostenta taxas altíssimas de pobreza, com a maior desigualdade social entre os países que compõem o G7, ${ }^{1}$ figurando em quinto lugar mundial no tocante à mortalidade infantil. ${ }^{2}$ Estima-se que cerca de 40 milhões de pessoas vivem abaixo da linha da pobreza no país, fato agravado pela crise da Covid-19, quando a taxa de desemprego pulou de $3,5 \%$ para mais de $8 \%$, ultrapassando o período de 1930 , conhecido como a Grande Depressão. Obviamente, a crise, assim como o acesso aos recursos para superá-la, afeta de forma desigual a população, da qual fazem parte os (as) trabalhadores(as) mais vulneráveis, sem direito à quarentena, embora sejam considerados(as) essenciais na agricultura, no comércio e no setor de serviços. Cotidianamente, vivem a angústia de ter que decidir entre trabalhar e correr o risco da contaminação ou ficar em casa sem recursos suficientes para a sobrevivência (CONDE; VENDRAMINI; 2020).

No geral, prevalece entre a população norte-americana branca, detentora dos grandes meios de comunicação e de produção da ideologia e da hegemonia, a ideia da responsabilização individual da pobreza. É como se, por alguma motivação desconhecida e dada a priori, uma certa elite laboriosa tenha acordado cedo para trabalhar e, por isso, prosperou e enriqueceu, enquanto outra parcela da população, preguiçosa, fanfarrona, vagabunda e desprovida de razão, padece na miséria dos guetos, onde predominam as festas, as músicas, a transgressão, a preguiça e a alegria. Conforme Marx (1988), a história do esforço individual no trabalho como origem da riqueza, bem como da preguiça como fonte da pobreza funciona para a economia política como uma espécie de teoria criacionista e dos sete pecados capitais, presentes nas escrituras sagradas.

Como compete à ciência ir além da aparência, desvelamos que não é o trabalho a origem da riqueza, mas a exploração do trabalho (ou seja, a produção da mais-valia). Esse segredo, velado por todos os economistas burgueses que antecederam o velho barbudo, prestou um grande favor à

\footnotetext{
${ }^{1}$ Grupo dos países mais industrializados do mundo: Estados Unidos, Alemanha, França, Itália, Canadá, Reino Unido e Japão. Excluem-se desse grupo Rússia e China, por razões históricas, que envolvem a luta entre Socialismo e Capitalismo e a disputa pela hegemonia mundial.

2 Nos Estados Unidos, a mortalidade infantil entre crianças negras é duas vezes maior do que entre brancas.
} 
burguesia white supremacist na Europa e perdura até a atualidade nas Américas. Para compreender a origem da riqueza, é necessário compreender a acumulação primitiva do capitalismo, coincidente com 0 advento da propriedade privada individual; do modelo de família burguesa, monogâmica e controladora dos corpos femininos e da descendência; do racismo, que escravizou negros e índios nas colônias; e da ideologia do amor ao trabalho, presente na educação, na legislação e na religião da classe trabalhadora europeia que migrara, entre os séculos XVIII e XIX, para as Américas (CONDE, 2016).

O mesmo raciocínio pode ser feito em relação às vítimas da Covid-19. Conforme dados divulgados semanalmente pela prefeitura de Nova York (2020), o número de atingidos é duas vezes maior entre negros(as) e latinos(as) do que entre brancos(as) americanos(as), evidenciando o que Wilhians (2020) chama de racismo estrutural e institucional no número de contaminados(as) (em virtude de a população negra e latina ter menos condições de realizar quarentena, por viver nas piores condições de trabalho, renda e moradia); no número dos(as) que conseguem atendimento e tratamento (num país sem sistema público universal de saúde, negros(as) e imigrantes são impedidos(as) de acessar os serviços de tratamento); no número de curados(as) e mortos(as) (após acessarem o serviço dos hospitais quando ocorre uma segregação oriunda do fato de os médicos e enfermeiros serem formados para atender brancos(as) e ricos(as), critério que pesa na hora de escolherem quem deverá ser tratado primeiro). Também são comuns os casos de médicos que acreditam que negros(as) possuem mais resistência à dor do que os(as) brancos(as) e, por isso, utilizam dozes menores de anestésicos e equipamentos durante procedimentos cirúrgicos ou tratamentos (CONDE; CASSINI; 2021).

Wilhians (2020), advogado e ativista do movimento negro nova-iorquino, destaca que os dados sobre os(as) contaminados(as) devem ser interpretados cuidadosamente, pois o problema racial é errônea e comumente atribuído pela supremacia branca à origem biológica e hereditária - ou seja, uma nova eugenia operante -, quando, na realidade, ele é produto de uma estrutura 
social desigual, racista e xenófoba, que condena pobres, negros(as) e latinos(as) às piores condições de vida e de acesso à saúde, alimentação, moradia e direitos.

A desigual realidade norte-americana, acompanhada de uma culpabilização individual do fracasso, é parte cotidiana da vida de milhares de estudantes não brancos(as) (negros(as), latinos(as) e demais minorias étnicas não pertencentes à white supremacist), entre os(as) quais se encontram a maior parte dos(as) alunos(as) matriculados no Community College da CUNY, participantes dos dados que compõem este texto. O processo que intitulamos de neocolonialismo revela a persistência das opressões coloniais, nas quais a exploração e a expropriação de negros(as), indígenas e não brancos(as) se reproduz não mais apenas no interior das colônias latinas, asiáticas e africanas tal o que conhecemos por período das "grandes navegações", mas também no interior dos países ricos capitalistas. É como se houvesse um muro interno e invisível segregando o Sul dos colonizados no interior do Norte Global colonizador. É neste real e desigual que entendemos ser possível falar de um colonialismo no contexto dos EUA.

É neste que se encontra o Community College da CUNY, composto, principalmente, de alunos(as) de baixa renda, muitos(as) dos(as) quais filhos(as) de imigrantes de primeira geração, que enfrentam uma miríade de desafios relacionados à sobrevivência e à escolarização num país fortemente marcado pela desigualdade, pelo individualismo e pela meritocracia (ENGLE; TINTO, 2008). Conforme dados coletados pela própria La Guardia Community College, $81 \%$ dos(as) alunos(as) relatam renda familiar inferior a US\$25 mil, e mais de $50 \%$ são nascidos(as) no exterior, com mais de cem línguas nativas diferentes. Essas faculdades comunitárias, que abrangem o que no Brasil constitui o ciclo básico dos currículos de graduação, e, portanto, deveriam levar dois anos para serem completadas, atraem alunos(as) que não podem se matricular diretamente em faculdades de quatro anos, porque não cumpriram os requisitos de admissão. Além disso, como os Community Colleges são menos caros do que os cursos de quatro anos, eles parecem oferecer aos(às) alunos(as) da classe trabalhadora a oportunidade de pagar mensalidades 
baixas enquanto trabalham (SOLORZANO; VILLALPANDO; OSEGUERA, 2005).

Consequentemente, as faculdades comunitárias matriculam predominantemente alunos(as) de baixa renda, que são os(as) mais diversos(as) em termos de idade, raça e etnia, capacidade e aspirações de carreira. As barreiras enfrentadas por eles(as) vão desde a necessidade de aulas de reforço até problemas financeiros e de moradia. Enquanto $70 \%$ dos(as) novos alunos(as) de Community Colleges expressam a intenção de se transferirem para uma faculdade de quatro anos, a fim de buscarem um diploma de bacharelado, apenas $15-25 \%$ acabam realmente se transferindo ao longo de um período de quatro anos (NCES, 2001, p. 197). Além disso, 45\% dos(as) alunos(as) de Faculdades Comunitárias costumam deixar a instituição sem se graduarem após três anos (NCES 2009, p. 152). Isso confirma uma tendência a taxas de evasão continuamente altas, motivadas pelo fato de os(as) estudantes universitários(as) oriundos de diferentes setores da classe trabalhadora empreenderem uma luta desproporcional, na qual o tempo, os recursos e a dedicação aos estudos competem com o tempo de trabalho e de manutenção da vida, transformando-os(as) em estudantes pela metade.

Dada a origem socioeconômica dos(as) alunos(as) e as preocupações imediatas relacionadas à saída da pobreza, o discurso da estabilidade financeira e da mobilidade ascendente molda poderosamente - e em muitos casos domina - as práticas institucionais, promovendo objetivos de aprendizagem pragmáticos e noções instrumentais de sucesso. Tal orientação, destinada a estudantes de baixa renda, estritamente instrumental e com ênfase em habilidades técnicas, contrasta com a agenda educacional liberalconstrutivista destinada aos(às) filhos(as) das elites, com objetivos mais amplos e de longo prazo, como aprendizagem ao longo da vida e competências integrativas, engajamento cívico e assim por diante. Muitos(as) alunos(as), apanhados(as) em meio a essas agendas conflitantes, vacilam entre essas duas posições opostas e lutam para assumir um posicionamento coerente em relação ao aprendizado. Essa realidade, é vivenciada como um esvaziamento da agência estudantil, acarretando um alto grau de alienação e 
opressão à educação universitária. Encaradas pelos(as) alunos(as), respectivamente, como ampla demais ou demasiadamente restritiva, as agendas educacionais liberal e instrumental passam a ter um sentido quase irrelevante para suas respectivas agendas de vida estudantis (VIANNA; HOUGAARD; STETSENSKOO, 2014).

\section{CONTEXTO HISTÓRICO DA PATOLOGIZAÇÃO DA POBREZA}

O contexto histórico de patologização da pobreza, da diferença, da diversidade e das desigualdades não é recente na história dos Estados Unidos. O país, ancorado num padrão branco colonialista, atendendo às demandas do sistema capitalista de produção, relativas à concentração da riqueza nas mãos de poucos e à exploração de muitos, desenvolveu uma série de pesquisas e teorias sociológicas, psicológicas e educacionais que serviram para consolidar um padrão cultural escolar extremamente excludente e elitista.

Keeanga-Yamahtta Taylor (2020), destaca como a concepção de cultura contribuiu para uma ideologia racista sobre a pobreza nos Estados Unidos da América. Segundo a autora, o sonho do American way of life e toda a ideologia construída após a Segunda Guerra Mundial, que apregoava que a América do Norte seria o lugar em que tudo seria possível e que todo sonho, a depender do esforço individual de cada um, poderia ser realizado, serviu para disseminar uma ideologia racista da pobreza (culture of poverty), localizando-a em padrões de comportamento imputados à população negra. Entendendo a cultura como uma característica humana natural e dada a priori, retira-se a discussão sobre como as condições materiais de vida e toda subjetividade são socialmente produzidas. Assim, aquilo que pode e é constantemente transformado pelo movimento dialético e contraditório da vida social aparece como natural e imutável.

Essa noção de cultura da pobreza entrou em voga nos Estados Unidos a partir da política do presidente Lyndon Johnson, nos anos 1960, que declarou 'guerra à pobreza no país'. Tal ideia passou então a constar como frequente explicação para o fracasso escolar, que historicamente atinge de maneira 
desproporcional alunos(as) de minorias étnicas e imigrantes, os(as) quais vivem abaixo da linha da pobreza. Ou seja, o baixo rendimento escolar de alunos(as) minoritários(as) era atribuído à suposta pobreza cultural de suas famílias e comunidades, que, segundo esse tipo de argumento estereotipado, não recebiam suficiente estimulação, não tinham acesso a léxico amplo e gramática estruturada, não liam em casa, etc. Essas teorias de déficits culturais têm uma longa história no país e remetem à escravidão e ao racismo. Elas permaneceram nas políticas culturais durante os anos 1970 e continuam ainda hoje, embora de forma mais velada, em argumentos sobre o porquê de as crianças que vivem em condições de pobreza, em sua maioria negras e latinas, não aprenderem em casa o que é necessário para o sucesso escolar.

\section{DEFICIÊNCIA DE APRENDIZAGEM: A PATOLOGIZAÇÃO DOS DESAFIOS DE ENSINO-APRENDIZAGEM}

Ray McDermott (1993), ao estudar a rotina intensa de aulas e testes de Adam, uma criança diagnosticada com deficiência de aprendizagem pelo sistema educacional norte-americano, afirma que não existe aprendizagem sem ensino ou fora de contexto. Assim, o autor defende que faz mais sentido falar em como o conhecimento (ou o contexto) afeta ou adquire a pessoa do que em como a pessoa adquire o conhecimento. A categoria deficiência de aprendizagem existe culturalmente na sociedade e corresponde a padrões de práticas, tarefas e habilidades aos quais as crianças devem corresponder desde pequenas. Nas observações realizadas por McDermott (1993) sobre a rotina de Adam, relatadas em seu clássico artigo, intitulado A aquisição de uma criança por uma deficiência de aprendizagem, ele argumenta que a criança é, muitas vezes, adquirida pela deficiência presente no contexto. Assim, o autor percebe como o grupo de colegas e professores em sala prestam mais atenção no que Adam não consegue fazer, ou no que se espera que ele consiga, do que no que ele de fato consegue fazer. McDermott (1993) observa uma série de tarefas que Adam executa cotidianamente com sucesso, mas que não correspondem às expectativas institucionais e sociais. Os colegas presentes nas atividades compartilhadas também enfatizam os seus erros, seja através 
de previsões sobre o que ele vai fazer, seja destacando seus erros posteriormente. Quando o foco do pesquisador é alterado para o que Adam consegue fazer, é possível observar o silenciamento social sobre suas atividades de sucesso.

Talvez nada disso importasse tanto se não existisse toda uma rede discursiva imbricada com uma cadeia de práticas sociais, entrelaçando vários sistemas institucionais, como a educação, a saúde mental e a assistência social, que vêm progressivamente adotando uma forte visão biomédica no que diz respeito aos desafios dos jovens na escola e nas demais instituições sociais. O próprio fato de professores e colegas prestarem mais atenção ao que Adam não dá conta de desempenhar com eficácia do que no que de fato ele consegue executar bem já é resultado, segundo McDermott (1993), da própria estruturação das expectativas e percepções, nas instituições de ensino, em torno de déficits e patologias. Isso decorre da crescente tendência a encarar desafios educacionais, e o sofrimento humano de modo geral, como entidades biomédicas que precisam ser diagnosticadas e tratadas com psicofármacos, conforme a visão amplamente difundida pela globalização ou americanização da abordagem psiquiátrica, que, ainda por cima, é altamente financiada com recursos da indústria farmacêutica (SUMMERFIELD, 2012).

Em vista disso, McDermott (1993) argumenta que é esse arcabouço prático-discursivo que se apropria das (ou adquire) as crianças que, pelas mais diversas razões, não se conformam ao padrão de comportamento esperado por profissionais de ensino, incluída aí toda a gama de profissionais de saúde mental a quem tais alunos(as) são encaminhados(as).

É fácil compreender como tais diagnósticos de déficits de aprendizagem, desordem de hiperatividade e déficit de atenção, entre outros distúrbios, funcionam como rótulos em torno dos quais a identidade do(a) educando(a) vai sendo relacionalmente moldada por discursos e práticas institucionais, que são então adotados pelas famílias e pelos(as) próprios(as) jovens assim diagnosticados(as). É dessa forma que se pode dizer que a vítima acaba sendo culpabilizada por sua própria condição, que se torna assim uma profecia autorrealizante (Vianna, 2009). 
Com ênfase no contexto de ensino-aprendizagem e problematizando os padrões excludentes do sistema norte-americano, Goessling (2019) relata a participação de jovens traumatizados(as) pela violência colonial, sexista e racial e mostra caminhos de superação por meio de grupos juvenis de arte e de pesquisa-ação. A autora destaca o aumento da violência racial, colonial e sexista após as eleições de Donald Trump, em 2016, e os efeitos dessa toxina social à saúde juvenil. Ainda nesse sentido, ilustra a importância de compreender os caminhos que os(as) próprios(as) jovens usam para resistir e responder ao que lhes acontece. Crescer num ambiente de pobreza é um grande desafio para a juventude, pois o acesso as oportunidades e aos recursos são vitais para a aprendizagem e o desenvolvimento. Para a autora, os espaços juvenis de arte e pesquisa contribuem para a humanização dos(as) jovens, na medida em que eles(as) entendem melhor a si mesmos(as) e ao mundo num clima de liberdade, sem padrões e avaliações relativas ao desempenho e ao resultado final. Assim, exercitam a imaginação política comprometida com a transformação social num mundo melhor e de acordo com seus próprios anseios e buscas (STETSENKO, 2017).

Ao perceberem que suas próprias histórias individuais não estão isoladas, mas recebem influência do que ocorre no mundo e na história, os(as) jovens passam a perceber melhor a indissociabilidade entre o Eu e o Outro, entre indivíduo e coletivo, como uma unidade de contrários em que a consciência se desenvolve na atividade social prática e cotidiana.

Para Goessling (2019), o sucesso da participação de jovens na pesquisa ativa é calçado em três pilares: 1) comprometimento dos(as) jovens com problemas sociais (que a partir do pensamento crítico se percebem como seres de agência, que analisam o contexto e se engajam coletivamente para mudálo); 2) ênfase na relação pessoal-social, na qual percebem as contradições aí envolvidas; 3) a própria voz como elemento central para identificar e solucionar problemas. Com isso, não se espera desenvolver jovens especialistas em pesquisa, mas sim permitir que eles(as) se percebam como parte ativa de um processo em transformação, no qual a relação entre indivíduo-coletivo e sociedade é fundamental para a humanização e a emancipação. 
$\mathrm{Na}$ medida em que o(a) jovem conhece mais sobre o mundo e sobre 0 Outro, ele(a) amplia seus referenciais, compreende a si mesmo(a) e faz escolhas mais conscientes sobre o que pretende mudar ou continuar. Entende que as violências cotidianas sofridas não são demérito individual, mas produtos sociais que afetam outras pessoas em proporções maiores, menores ou iguais. Com isso, é possível criar uma nova identidade individual-coletiva, na qual o que se deseja para o próprio futuro individual se conecta com o que se deseja para o mundo. Se, historicamente, os(as) jovens sempre criaram seus próprios espaços de resistência, por meio de protestos, ocupações de escolas, grafites, danças e músicas, nos espaços coletivos de pesquisa, em meio a um espírito libertário, ético e comprometido socialmente, podem vislumbrar e lutar por um novo mundo possível.

É exatamente nesse sentido que Stetsenko (2017), ao tratar do TAS na história da psicologia, critica como a área tem contribuído para insuflar visões elitistas, racistas e sexistas, com abordagens falsas sobre questões sociais e de injustiça. Assim, defende que o conhecimento ocorre de forma colaborativa e compartilhada, em práticas realizadas por indivíduos. Essa inseparável mistura faz com que cada um(a) contribua de forma única para a sociedade e seja, ao mesmo tempo, produzido(a) por ela. Assim como é falsa a oposição entre natureza e cultura, o mesmo ocorre com relação ao indivíduo, à sociedade e à produção do conhecimento. O conhecimento não é produto de uma iluminação interna dos sujeitos, dada a priori; pois assim como a mente está no cérebro, o cérebro está no corpo, e o corpo está na sociedade.

Os testes padronizados de aprendizagem, ao contrário do espírito de camaradagem anticolonial, antirracista, antissexista e anticapitalista dos autores abordados neste artigo, desconsideram os contextos de vida das crianças e dos(as) estudantes e, sob uma falsa e pretensa abordagem neutra, acabam por privilegiar crianças da classe média branca, cujas famílias já possuem acesso historicamente à escola e ao tipo de conhecimento por ela ensinado. Parafraseando Stetsenko (2017), o conhecimento não diz respeito a ideias soltas no espaço, mas sim ao drama da vida humana. Ele é um processo socioindividual, interativo, compartilhado, historicamente situado na 
materialidade da vida e das nossas lutas e buscas. Ele sempre parte de nossos contexto e práticas e situa-se num fluído único e interminável, que envolve passado, presente e futuro; ou seja, é movimento e, portanto, está em constante transformação e distante de dogmas, verdades absolutas e padrões de aprendizagem.

\section{DESPATOLOGIZANDO A DIFERENÇA E A POBREZA PELA APRENDI- ZAGEM COLETIVA E COMPARTILHADA}

No ano de 2020, durante o estágio como professora visitante na CUNY, a primeira autora deste paper participou de reuniões semanais no PALC, coordenado pelo segundo autor, que acolhe estudantes matriculados nos primeiros anos das Faculdades Comunitárias, com o objetivo de romper com a lógica de individualização, rotulação e patologização daqueles(as) que diferem dos padrões de aprendizagem normatizados pelo sistema educacional norteamericano. Entre os(as) estudantes com que trabalhamos durante 2020 no PALC, chamou-nos a atenção o caso de duas jovens, que foram por nós entrevistadas. A primeira delas, parte das frações mais empobrecidas da classe trabalhadora, fora diagnosticada com deficiência de aprendizagem desde a Educação Infantil, durante a qual foi submetida a testes padronizados de aprendizagem e a avaliações fora de contexto. Esse tipo de avaliação, predominante no sistema educacional norte-americano, desconsidera tudo 0 que a criança sabe fazer em seu contexto prático e no cotidiano de sua vida (assim como no caso de Adam, descrito por McDermott no item anterior) e exige conhecimentos que favorecem a classe média branca americana. Mais tarde, no Ensino Médio, essa estudante recebeu diagnósticos de ansiedade e depressão e passou a ser medicada.

$\mathrm{Na}$ entrevista que concedeu aos autores deste artigo, no dia 7 de novembro de 2020, a estudante contou que, quando começou a frequentar as aulas no Community College, costumava entrar em desespero e chorar, pois se sentia sozinha, perdida e sendo prejudicada por um sistema que desconsiderava sua especificidade, suas dificuldades e facilidades, bem como seu contexto de vida: 
Acho que o sistema está me ferrando! O problema começou quando eu era criança, quando eu tinha 4 anos, em 1989, no jardim de infância, em Connecticut, quando fiz um teste com o pessoal de lá. Não me lembro muito bem, mas me lembro dos blocos que normalmente usava. Fiz um teste com blocos no jardim de infância [...] os blocos sobre as quantidades que eu precisava jogar com meus amigos. Essa é a primeira coisa que me lembro da escola, na mesa das crianças com três ou quatro adultos na minha frente. E tive que fazer alguns testes com os blocos que eles me mostravam. Senti pressão, porque tinha que fazer isso na frente deles. Eu era tão criança, e ia para o jardim de infância da manhã [...], fazia xixi nas calças e era mais lenta todos os dias com o pessoal de lá, porque eu não tinha meus pais perto de mim para ajudar nas tarefas todas as noites, como as outras crianças tinham. Eu lia muito devagar e tinha dificuldade com números. Lembro-me de uma coisa específica com a professora, porque fiz meu número $8 \mathrm{com}$ dois círculos, e a professora me disse: "Você sabe que pode fazer isso de uma maneira diferente, tipo, melhor?". E eu era uma criança pequena! Fui levada para uma sala de aula diferente, para a hora de leitura e a hora de matemática e a aula regular. $\mathrm{E}$ eu fiz minha leitura e aula de matemática em uma sala separada, com algumas outras crianças. Eu me senti meio estranha, meio extraordinária! $E$ meu irmão era uma criança no Programa de superdotados e talentosos. Eu era mais lenta e sempre estava atrás dele na minha família. E então, quando eu tinha 9-10, quando os testes padronizados começaram e eu fiquei apavorada, tinha ataques de pânico com os testes [...], com medo de não ser boa o suficiente para fazer o teste [...]. Achei que isso estivesse acontecendo porque meus pais eram divorciados [...], e a administração da escola disse a minha mãe para me medicar por causa dos meus ataques de pânico durante os testes [...]. E, nas escolas, as pessoas diziam a ela: "Sua filha tem ataques de pânico e tem alguma coisa errada, e você precisa dar esse tipo de remédio para ela". E minha mãe respondia: "Não!". Ela resistia constantemente e dizia: "Minha filha precisa de outra sala de aula e de um novo professor [...]". Nos testes, sempre me sentia sob ameaça, com medo e, tipo, nua, certo? Não me lembro de experiências boas nas escolas [...], não tinha muitos amigos [...]. Ir para a escola era uma experiência terrível, porque, se você é uma criança com problemas, você é estigmatizada e fica separada, eu me sentia nua [...].

Além de sentir nua, sozinha, separada e extraordinária, a estudante ressalta o quanto sua família tentou resistir aos medicamentos, até que ir à escola e continuar estudando se tornou algo impossível para ela. Ir à escola significava exposição, humilhação e vergonha. A escola, ao mesmo tempo em que tem seus limites dados pela infraestrutura e pelas condições de vida e de 
trabalho dos(as) docentes e alunos(as), é cúmplice ao seguir o caminho mais prático e rápido, retirando as crianças da sala e medicalizando quem não se encaixa dentro dos padrões esperados. O sonho de formar-se na faculdade, somado às dificuldades encontradas num sistema padronizado, que insiste em rotular e diagnosticar situações diferentes, foi fundamental para o início dos medicamentos:

Minha mãe resistiu com a medicação, mas depois comecei [a usar] [...], quando a escola era péssima para mim e era impossível continuar a frequentá-la. Minha mãe lutou muito contra o diagnóstico, mas os relatórios condenavam minha opinião sobre mim. E minha mãe me levou para a escola muito cedo, porque ela precisava trabalhar. Ela precisava das escolas, porque ela precisava trabalhar para ganhar dinheiro. A escola, para mim, foi uma experiência vergonhosa. Acho que vergonha é a palavra perfeita para descrever isso [...]. Lembro-me da primeira vez que senti isso, eu era bem mais jovem [...]. A escola precisa entender as crianças, porque a escola é cúmplice do sistema, e não quero culpar os professores, eles estão jogando o jogo do sistema. Eu sei que todo mundo [como os professores] está apenas tentando sobreviver, pagar as contas, conseguir um emprego. As pessoas e o professor estão apenas tentando sobreviver em um sistema de merda, real [...]. Aos 14 anos, eu estava indo bem na escola e morando com meu pai. Depois, mudei de escola novamente, porque minha mãe decidiu que eu precisava ir para aquela outra escola, me mudei novamente e comecei a me sentir muito mal. [...] Quando eu era uma criança, eu estava em uma escola muito pequena, durante 0 primário, com famílias muito ricas, uma escola muito influente, e eu era diferente naquele contexto, pois eu não estava naquele padrão [...], mas depois eu estava em uma escola muito grande, com tanto mais situações de diversidade e com amigos diferentes e de diferentes contextos e situações. No último ano do colégio, quando mudei de colégio, voltei para um colégio pequeno, em uma região rica e branca, aí comecei a faltar às aulas, e aí acho que, naquele ano, comecei a tomar o remédio. E decidi experimentar o remédio, porque as pessoas diziam isso para mim há tanto tempo [...], quando decidi [que] estava deprimida! Recebi o diagnostico de depressão e ansiedade. Meu pai me apoiou muito [...], e ele me perguntou o que eu queria fazer [...], e eu decidi tentar isso, porque eu estava me sentindo disléxica, talvez, e uma pessoa diferente e entristecida [pausa]. E meu pai nunca se formou no Ensino Médio, e eu estou na faculdade. Eu pensei que precisava tomar o remédio para terminar Ensino Médio, porque isso é importante para mim e meu pai [...]. Alguns dias antes das aulas começarem no College, eu me senti empolgada [...], mas, 
depois do início, na primeira semana, senti vergonha, me senti sozinha e pensei: "Ai, meu Deus, não! [pausa]. Ai, meu Deus, de novo não! Estou sentindo as mesmas coisas de novo". (grifos nossos).

Como detalha a pesquisadora de estudos críticos das deficiências Dušana Podlucká (2020), a ideologia institucional dominante materializada em práticas de Disability Student Services Office (DSSO), perpetua a deficiência e as práticas educacionais opressivas. Os administradores e educadores do DSSO normalmente operam a partir de perspectivas que resultam de uma compreensão individualista, estática, descontextualizada do processo de aprendizagem, como evidenciado nas práticas de provisão de acomodações individualizadas e no conceito de estilos de aprendizagem, notoriamente reconhecido por suas limitações conceituais, já ultrapassadas, mas ainda fortemente influentes.

Conforme a autora, o papel principal do DSSO é garantir que as faculdades ponham em prática a lei e as políticas legislativas destinadas a fornecer acesso à educação para alunos(as) com diagnóstico de deficiência. No entanto, para que os(as) alunos(as) recebam os serviços e a assistência do DSSO, que supostamente permitem 'acesso igual' à educação, devem fornecer a documentação de uma deficiência diagnosticada. Segundo argumenta Podlucká (2019, p. 72), que estudou o caso de uma aluna com diagnóstico de autismo em uma Faculdade Comunitária de Nova York,

[...] uma implicação desta legislação, ou a própria base dela, é a afirmação de uma identidade de deficiente, que é reestabelecida e confirmada a cada semestre, a fim de manter o acesso aos serviços e acomodações, fornecendo-se a necessária documentação. Pode-se argumentar que um aluno tem que se posicionar como marginalizado para obter acesso aos recursos, às ferramentas e aos espaços necessários para ser incluído na aprendizagem, que estão prontamente disponíveis para outros alunos. Ironicamente, os alunos têm que praticar uma forma de autoexclusão ao terem que se identificar como alunos não normativos, a fim de acessar recursos de inclusão. Embora o papel do DSSO seja possibilitar a igualdade, o discurso oficial do DSSO e suas práticas institucionais localizam a deficiência dentro dos alunos individuais, posicionando-os, assim, como os "proprietários" da deficiência. Indiscutivelmente, isso limita sua participação na 
aprendizagem e outras práticas institucionais, estabelecendo uma posição desigual e marginalizada do aluno com deficiência desde 0 início. Reivindicar a identidade de "aluno com deficiência" é uma posição inicial de que esses alunos se envolvem em atividades de aprendizagem que, em seguida, são incorporadas em sua construção de identidade como alunos - um "aluno com deficiência" que enfraquece e, em última análise, incapacita a aprendizagem.

Com o tempo, essa identidade de portador(a) de deficiência ou transtorno psicológico vai se cristalizando, à medida que passa a mediar de forma cada vez mais ampla as relações dos(as) alunos(as) com professores(as), colegas e demais profissionais que lhes provêm serviços na universidade. Como a deficiência e a patologia são vistas como estáticas, já que seriam biologicamente determinadas, não se tenta abordá-las de forma a serem enfrentadas a partir da transformação das próprias práticas de ensinoaprendizagem. Para agravar a situação, se o(a) aluno(a) supera a deficiência ou patologia, ele(a) perde o acesso aos recursos e acomodações especiais a que tem acesso. Ou seja, esse sistema torna o(a) aluno(a) presa da própria assistência que tem a seu dispor, o que chamamos de cooptação neocolonial da agência desse(a) estudante.

Voltando ao caso da estudante por nós entrevistada, ela reconhece o erro do sistema em encaminhá-la à medicalização, da qual se tornou dependente. No entanto, ela resiste e encontra na possibilidade de concluir o curso de Psicologia, bem como no suporte dado pelos colegas do PALC, um meio para traçar uma trajetória diferente, que contribua para a construção de uma nova escola e uma nova psicologia escolar:

Eu tenho esse plano agora [...] e quero trabalhar com crianças e quero ser professora, porque quero mudar o sistema [...], para fazer melhor, porque foi o sistema que me fez isso. $E$ o curso de Psicologia vai me dar uma boa base para ensinar. Eu quero trabalhar com crianças pequenas, porque não quero para elas a experiência que eu tive. Quero ter uma atitude crítica em meu trabalho nas escolas, e minha experiência pessoal pode me ajudar mais. Quando eu estava no jardim de infância, todos os problemas começaram com meu 8, por causa dos dois círculos [...], mas esse mesmo 8 [...] - aprendi que dois círculos são o 8 . Se a criança fez um 8 com dois círculos [...], ok! Parabéns! Este é um 8! Estou falando 
sobre aceitar formas diferentes, pessoas diferentes, maneiras diferentes de aprender [...] sem padrões rígidos. Junto com o PALC, estou aprendendo que o sistema que tentou me transformar em uma coisa/um problema individual [...]. Quando comecei no PALC, me senti mais confortável para fazer perguntas idiotas, que você não pode fazer na sala de aula. Após a experiência com o PALC, senti-me livre e capaz de pedir explicações sobre algo que algumas pessoas consideram um conceito básico. Porque, quando perguntava algo básico, me sentia mal. Eu me sentia sozinha na sala de aula. Depois do PALC, me sinto mais conectada, e não sozinha, alunos estranhos que estão sozinhos nesta cidade podem estar na mesa juntos, aprendendo, conversando sobre a aula, a pergunta, a resposta, desacelerando as coisas [...]. E me sinto mais à vontade no pequeno grupo de alunos em perguntar sobre o básico que preciso/devo saber. E na aula normal não me sinto confortável, então me sinto pequena.

Como é possível perceber pelo depoimento, depois de sua participação num grupo de estudos e pesquisa compartilhados, a aluna tem clareza de que foi avaliada, desde a Educação Infantil, com testes prontos e distantes de seu contexto de vida. Reconhece as falhas das padronizações, como no caso da escrita do número $8 \mathrm{com}$ dois círculos, da vergonha e da exposição a que estava submetida em frente dos(as) colegas de turma e dos(as) professores(as) avaliadores(as). Percebe, nos trabalhos com crianças que desempenha na atualidade, que a atividade cotidiana de cada indivíduo é o determinante do desempenho escolar. Exemplo disso está na percepção de que cada assunto novo introduzido para as crianças com quem trabalha atualmente requer delas um esforço grandioso de compreensão. Esse esforço requer acolhimento, paciência, afeto e cuidado por parte do adulto mediador ou do(a) professor(a).

A história descrita acima é apenas mais uma dentre tantas outras dos estudantes que frequentam os Community Colleges nos Estados Unidos e se encontram semanalmente na PALC. A PALC se baseia nos avanços da tradição vygotskyana, em particular no TAS (STETSENKO, 2008, 2017), que define aprendizagem e desenvolvimento como realizações colaborativas, com pessoas que executam agendas ativistas baseadas em uma visão de mundo transformadora da realidade. Conforme esta visão, o processo de ensinoaprendizagem diz respeito a conectar-se socialmente, engajar-se e, de forma 
crítica, estimular identidades agentivas, ao fornecer as ferramentas necessárias para a tomada de uma posição sobre o conhecimento, as práticas sociais e o mundo.

Nesse sentido, diferentemente dos relatos da estudante entrevistada, a aprendizagem ocorre apenas quando o conhecimento faz sentido e está inserido no contexto de vida dos(as) estudantes, de acordo com seus engajamentos práticos e projetos de vida. O conhecimento, então, é entendido como imerso em práticas sociais, contingente à própria agenda de cada aluno e realizado de forma única e socialmente posicionada (Vianna \& Stetsenko, 2019)

Durante as reuniões semanais, os(as) participantes da PALC se engajam em: (a) criticar as práticas sociais e os discursos dentro das instituições de educação e examinar as suposições pessoais que levam à desigualdade, à pobreza, ao racismo, ao sexismo e a outras formas de discriminação; (b) facilitar o posicionamento de cada um(a) (tomada de posição) sobre essas questões e aquelas relacionadas ao processo de ensinoaprendizagem; e (c) desenvolver agendas ativistas que incluam contribuições para práticas sociais passíveis de fazer a transformação social.

Incentivados por leituras teórico-críticas selecionadas para conectar, contextualizar e transformar seus conceitos de práticas educacionais, os membros da PALC investigam suas próprias experiências como estudantes da Faculdade Comunitária. Eles discutem os desafios e objetivos acadêmicos que se relacionam com suas vidas pessoais e com o mundo em geral e, inevitavelmente, compartilham as dificuldades com os cursos e com a conexão entre a aprendizagem universitária e suas aspirações de participação na vida comunitária. Testemunhamos uma série de posicionamentos entre os membros da PALC, que variavam da passividade cooptada, em razão do acesso aos recursos possibilitado pelo diagnóstico de deficiente, até a rebeldia. Quase todos(as) participantes compartilhavam de um sentimento geral de desconexão, incerteza e contradição em relação aos seus cursos e à experiência geral na instituição. E todos(as) compartilhavam de um senso restrito de agência em seus cursos, caracterizado pela falta de engajamento e 
por sentimentos de resignação, geralmente acompanhados de ressentimento para com seus(suas) instrutores(as), cujas raízes remetiam às suas experiências na Educação Infantil ou no Ensino Fundamental e Médio.

\section{CONSIDERAÇÕES FINAIS: SUPERANDO A COOPTAÇÃO NEOCOLONIAL DA AGÊNCIA}

Ao limitar as lutas políticas à transformação quase que exclusivamente identitária e não fazer uma crítica radical de como esse paradigma, centrado numa visão ainda essencialmente individualista, que compreende 0 desenvolvimento humano e os processos mentais (cognição, motivação, memória, etc.) como intrinsicamente condicionados por mecanismos programados no cérebro e geneticamente determinados, a educação liberal acaba servindo de instrumento para a cooptação da agência de alunos(as) e professores(as). Ou seja, a educação liberal, que vem se tornando o modelo dominante de reforma educacional do ensino pós-secundário nos Estados Unidos, não rompe com discursos e práticas de cunho biomédico e cientificista.

Sem compreender a aprendizagem como parte integral da expansão da agência humana, cuja finalidade é fornecer instrumentos (ferramentas culturais) para que cada indivíduo possa contribuir para a incessante transformação de práticas comunitárias e sociais guiadas por uma visão de futuro (veja-se Stetsenko, 2017, sobre o papel do sought after future nos processos de desenvolvimento e aprendizagem), a educação liberal evita e até mesmo impede a abordagem de questões mais amplas sobre como a educação se insere nas históricas lutas políticas mundiais, como o capitalismo, o colonialismo e o patriarcado.

Por parte de professores e profissionais que oferecem serviços psicológicos e sociais a alunos, este tipo de pesquisa-ação, de cunho ativista transformador, portanto abertamente guiado por um ethos político-ideológico de combate à desigualdade e à opressão, implica o risco e a tentação de se posicionarem diante de alunos desfavorecidos e de minorias nas Faculdades Comunitárias como se fossem 'salvadores brancos'. Tal lugar de superioridade por parte de quem dá ajuda e apoio frequentemente inibe e limita a 
possibilidade de crítica institucional (e autocrítica), posicionando somente os alunos como o foco da transformação. Nosso trabalho como pesquisadoreseducadores, seguindo um tipo de pesquisa-ação com agenda abertamente transformadora, visa constituir tal aliança, ao nos juntarmos à luta docente contra a exclusão (neo)colonialista.

Nesse sentido, os discursos e as práticas educacionais nas universidades norte-americanas funcionam como ferramentas culturais distorcidas ou pervertidas, que não potencializam a luta e a agência ativista, mas, ao criarem hierarquias, mascaradas como naturais, funcionam como uma forma sofisticada de (neo)colonização, que oprime de acordo com a classe, a raça/etnia, o gênero e a capacidade/deficiência.

\section{REFERÊNCIAS}

ARIEVITCH, I. M. Beyond the brain: an agentive activity perspective on mind, development, and learning. Londres: Springer, 2017.

CONDE. A escola e a exploração do trabalho infantil na fumicultura catarinense. Florianópolis: Em debate, 2016.

VENDRAMINI, C.; CONDE, S. Vítimas do coronavírus: A classe trabalhadora imigrante. Portal Desacato, Florianópolis, 2020. Disponível em: http://desacato.info/vitimas-do-coronavirus-a-classe-trabalhadora-imigrante-porcelia-vendramini-e-soraya-franzoni-conde/

CONDE; CASSIANI, S. I can't breathe: reflexões sobre (neo)colonialismo e Covid-19 a partir da cidade de Nova lorque, EUA. Revista Interdisciplinar em Educação e Territorialidade, Itahum, 2021. (no prelo).

FREIRE, P. A pedagogia do oprimido. Rio de Janeiro: Paz e Terra, 1970.

ENGLE, J.; TINTO, V. Moving beyond access: College success for lowincome, first generation students. Washington: The Pell Institute, 2008.

FANON, Frantz. Os condenados da terra. Trad. José Laurênio de Melo. Rio de Janeiro: Civilização Brasileira, 1968

FREIRE, P. Pedagogia do Oprimido. São Paulo: Paz e Terra, 2019. 
GOESSLING, K. Youth participatory action research, trauma, and the arts: designing youth spaces for equity and healing. International Journal of Qualitative Studies in Education, Londres, v. 33, n. 1, p. 12-31, out. 2019.

MARCASSA, L.; DALMAGRO, S.; CONDE; S. F. Juventude Pobre e Escolarização. Florianópolis: Em Debate, 2020.

MARX, K.; ENGELS, F. A ideologia alemã. 7. Ed. São Paulo: Hucitec, 1989.

MARX, K. O capital: crítica da economia política. São Paulo: Nova Cultural, 1988. (livro 1, v. 2)

MCDECDERMOTT, R. The acquisition of a child by a learning disability. In: CHAIKLIN, S.; LAVE, J. (Eds.). Understanding practice: perspectives on activity and context. Cambridge: Cambridge University Press, 1993.

NATIONAL CENTER OF EDUCATION STATISTICS. Profile of Undergraduates in U.S. Postsecondary Education Institutions, 2003-04: With a Special Analysis of Community College Students. (NCES 2006-184). Washington: IES, jun. 2006. Disponível em:

http://files.eric.ed.gov/fulltext/ED491908.pdf. Acesso em: 20 set. 2020. NEW YORK (município). NYC Health. COVID-19: Data. New York, 2020. Banco de dados sobre a pandemia de Covid-19. Disponível em: https://bit.ly/2Jf9xn8. Acesso em: 20 set. 2020.

THE IMPACT of the corona virus crises on development finances. OECD, 24 de junho de 2020. Disponível em: https://bit.ly/2LjYB9c. Acesso em: 200 dez. 2020.

PODLUCKÁ, D. Transformative Anti-Ableist Pedagogy for Social Justice. Outlines: Critical Practice Studies, v. 21, n. 1, p. 69-97, 2020.

PHILLIPPE, K. A.; Sullivan, L. G. National profile of community colleges: Trends and statistics. 4. ed. Washington: Community College Press, 2005.

QUIJANO, A. Em torno a la colonialidade del poder. Buenos Aires: Edições del Signo, 2019.

SANTOS, B. S. O fim do império cognitivo: a afirmação das epistemologias do Sul. Belo Horizonte: Autêntica, 2019.

SEIDMAN, E.; TSENG, V. A systems framework for understanding social settings. American Journal of Community Psychology, v. 39, Issue 3-4, p. 191-419, 2007.

SOLORZANO, D.; VILLALPANDO, O.; OSEGUERA; L. Educational inequities and Latina/o undergraduate students in the United States: a critical race 
analysis of their educational progress. Journal of Hispanic Higher Education, v. 4, n. 3, 272-294, jul. 2005.

SUMMERFIELD, D. Afterword: Against "global mental health". Transcultural Psychiatry, v. 49, n. 3-4, p. 519-530, 2012. Disponível em: https://bit.ly/3jkAdAW. Acesso em: 20 set. 2020.

STETSENKO, A. The transformative mind: Expanding Vygotsky approach to development and education. Cambridge: Cambridge University Press, 2017. STETSENKO, A. From relational ontology to transformative activist stance: Expanding Vygotsky's (CHAT) project. Cultural Studies of Science Education, n. 3, 465-485, 2008.

STETSENKO, A. The challenge of individuality in cultural-historical activity Theory: "Collectividual" dialectics from a transformative activist Stance.

Outlines: Critical Practice Studies, v. 14, n. 2, p. 7-28, 2013.

TAYLOR, K.-Y. Raça, classe e marxismo. Trad. Maíra Mee. Revista Outubro, Rio de Janeiro, n. 31, $2^{\circ}$ sem. 2018.

US CHAMBER OF COMMERCE FOUNDATION (2013). Skills for America's Future. Retrieve August 31, 2013, from http://education.uschamber.com/initiative/plan-develop-skills-americas-future.

VENDRAMINI, C.; POLE, A. Vítimas do coronavírus: a classe trabalhadora migrante. Portal Desacato, 30 abr. 2020.

VIANNA. Collaborative transformations in foster care: teaching-learning as a developmental tool in a residential program. Saarbrücken: VDM Verlag, 2009.

VIANNA, E.; HOUGAARD, N.; STETSENKO, A. The dialectics of collective and individual transformation. In: BLUNDEN, A. Collaborative projects: an interdisciplinary study. Boston: Brill, 2014.

VIANNA, E.; STETSENKO, A. Connecting learning and identity development through a transformative activist stance: Application in adolescent development in a child welfare program. Human Development, v. 54, n. 5, p. 313-338, 2011.

VIANNA, E.; STETSENKO, A. Research with a transformative activist agenda: Creating the future through education for social change. Learning in and across contexts, n. 113, 575-602, 2014.

VIANNA; STETSENKO, A. Turning Resistance into Passion for Knowledge with the Tools of Agency: Teaching-Learning about Theories of Evolution for socialjustice among foster youth. Perspectiva, Florianópolis, v. 37, n. 3, p. 864886, 2019. 
VIGOTSKI, L. S. A formação social da mente. São Paulo: Martins Fontes. 2002

WHITT, E. J. Academic and student affairs partnerships. In: SCHUH, J. H. (ed.). Student services: a handbook for the profession. San Francisco: Jossey-Bass, 2011.

WILHIANS, J. Letter to Major Bill de Blasio. Inquiry regarding disparities in COVID-19 testing. April/2nd/2020.

Recebido em: 05/02/2021

Aprovado em: 17/06/2021 